\title{
Estimation of health effects (morbidity and mortality) attributed to PM10 and PM2.5 exposure using an Air Quality model in Bukan city, from 2015-2016 exposure using air quality model
}

\author{
Bahram Kamarehie $^{1}$, Mansour Ghaderpoori ${ }^{1 *}$, Ali Jafari ${ }^{1}$, Mohammadamin Karami ${ }^{1}$, Aliakbar Mohammadi ${ }^{2}$, \\ Khaled Azarshab ${ }^{3}$, Afshin Ghaderpoury ${ }^{4}$, Najaf Noorizadeh ${ }^{5}$
}

\begin{abstract}
${ }^{1}$ Assistant Professor of Environmental Health, School of Health and Nutrition, Lorestan University of Medical Sciences, Khorramabad, Iran

${ }^{2}$ Lecturer, Department of Environmental Health Engineering, Neyshabur University of Medical Sciences, Neyshabur, Iran ${ }^{3} \mathrm{MSc}$ of Water and Wastewater, Faculty of Environment, Islamic Azad University, West Tehran Branch, Tehran, Iran ${ }^{4} \mathrm{MSc}$ of Environmental Health Engineering, Students Research Committee, Shahid Beheshti University of Medical Sciences, Tehran, Iran

${ }^{5} \mathrm{MSc}$ of Occupational Health Engineering, Department of Occupational Health, School of Health, Shahid Beheshti University of Medical Sciences, Tehran, Iran
\end{abstract}

\begin{abstract}
Background: Air Quality software is a useful tool for assessing the health risks associated with air pollutants. Quantifying the effects of exposure to air pollutants in terms of public health has become a critical component of policy discussion. The present study purposed to quantify the health effects of particulate matters on mortality and morbidity in a Bukan city hospital from 2015-2016.

Methods: Information regarding coordinates, exposed population, number of stations used in profiling, mean and maximum concentrations (annual, winter, and summer), annual 98th percentile, baseline incidence (BI) per 100000 per year, and relative risk was needed for use with the software.

Results: The average particulate matter concentration was higher in summer than in winter. The concentrations of $\mathrm{PM}_{10}$ in summer and winter were 84.37 and $74.86 \mu \mathrm{g} \mathrm{m}^{-3}$, respectively. The Air Quality model predicted that total mortality rates related to PM10 and PM2.5 were 33.3 and 49.8 deaths, respectively. As a result, $3.79 \%$ of the total mortality was due to $\mathrm{PM}_{10}$. In Bukan city, $2.004 \%$ of total deaths were due to cardiovascular mortality. The Air Quality model predicted that the deaths of 92.2 people were related to hospital admissions for respiratory disease.

Conclusion: The continual evaluation of air quality data is necessary for investigating the effect of pollutants on human health.

Keywords: Air pollution, Bukan, Morbidity, Particulate matter, Software, Public health

Citation: Kamarehie B, Ghaderpoori M, Jafari A, Karami M, Mohammadi A, Azarshab K, et al. Estimation of health effects (morbidity and mortality) attributed to PM10 and PM2.5 exposure using an Air Quality model in Bukan city, from 2015-2016 exposure using air quality model. Environmental Health Engineering and Management Journal 2017; 4(3): 137-142. doi: 10.15171/EHEM.2017.19.
\end{abstract}

Article History:

Received: 23 December 2016

Accepted: 5 April 2017

ePublished: 10 August 2017

\section{Introduction}

A dust storm is defined as air turbulence which spreads a large mass of dust in the atmosphere and reduces horizontal visibility to less than a thousand meters (1). Dust storms carry a lot of various materials. Annually, dust storms transport particulate matter approximately 800 trillion grams to Asia (2). The frequent occurrence of dust storms due to drought in the Middle East is causing environmental and health problems $(3,4)$. Particulate matter is one of the most important compounds in the atmosphere. It comprises microscopic solids or liquid matters suspended in the atmosphere (5). Furthermore, it consists of complex mixtures that may contain biological, metal, toxic, and/or acid materials (6). Sources of particulate matter can be man-made or natural (7). Particulate matter impacts climate and precipitation, has harmful effects on human health, animal health, and the environment (8-10), and constitutes the most important issues and challenges associated with air pollution $(11,12)$. $\mathrm{PM}_{10}$ and $\mathrm{PM}_{2.5}$ have average aerodynamic diameters of less 
than 10 and 2.5 microns, respectively $(13,14)$. Studies show that particulate matter can be associated with increased hospital admissions, physiological changes in the body, and different diseases, especially of the respiratory (15) and cardiovascular (16) system, asthma, and lung cancer mortality (17). According to a report by the World Health Organization (WHO), particulate matter contributes to approximately 800000 premature deaths each year (6). The report also estimated that $1.5 \%$ of deaths in the world are caused by air pollution (18).

Air Quality (or Air Q) software is a useful tool for assessing the health risks associated with air pollutants. Quantifying the effects on public health of exposure to air pollution has become a critical component in policy discussion. WHO/ Europe's software tool Air Q performs calculations that allow the quantification of the health effects of exposure to air pollutants, including estimations of the reduction in life expectancy. Air Q has two main parts. In the first part, the short-term effects of changes in air pollution (based on risk estimates from time-series studies) are estimated. In the second part, the long-term effects of exposure (using life-tables approach and based on risk estimates from cohort studies) are estimated (19).

Iran is a dry country, and drought has exacerbated its dryness in the past two decades. Soil erosion, uncontrolled increases in agricultural land, uncontrolled exploitation of groundwater, and the desiccation of rivers have caused an increase in dust storms. Lake Urmia is located in northwestern Iran and is one of the largest saline lakes in not only Iran, but also the world (20). Moreover, it is the largest lake in the Middle East $(21,22)$. Bukan city is located south of Lake Urmia. Currently, most parts of the lake have dried up because of drought. In addition to dust storms, salt storms are also on the rise. Both salt storms and salty dust storms can increase the negative health effects of exposure to them. The present study aimed to quantify the health effects of particulate matter on mortality and morbidity in a hospital in Bukan city.

\section{Methods}

\section{Location data}

Bukan city is situated in West Azerbaijan province at northwest of Iran ( $\left.36^{\circ} 32^{\prime} \mathrm{N}, 46^{\circ} 13^{\prime} \mathrm{E}\right)$. Figure 1 shows the location of the city and the nearby air quality monitoring station. At present, there is only one air quality monitoring station there. Bukan city has an area of $306.2541 \mathrm{~km}^{2}$. According to the latest census in Iran, the city's population is 224628 persons.

\section{Data collection and information processing}

In this work, $\mathrm{PM}_{10}$ data was obtained from the Bukan Environmental Department. Study stages were classified into 4 steps, shown in Figure 2. In Step 1 (data collection from monitoring station), data regarding hourly $\mathrm{PM}_{10}$ and $\mathrm{PM}_{2.5}$ concentrations (2015-2016) was received from the Bukan Environmental Department in a Microsoft Office Excel spreadsheet. In Step 2, the information was processed with MS Excel using the following procedure:

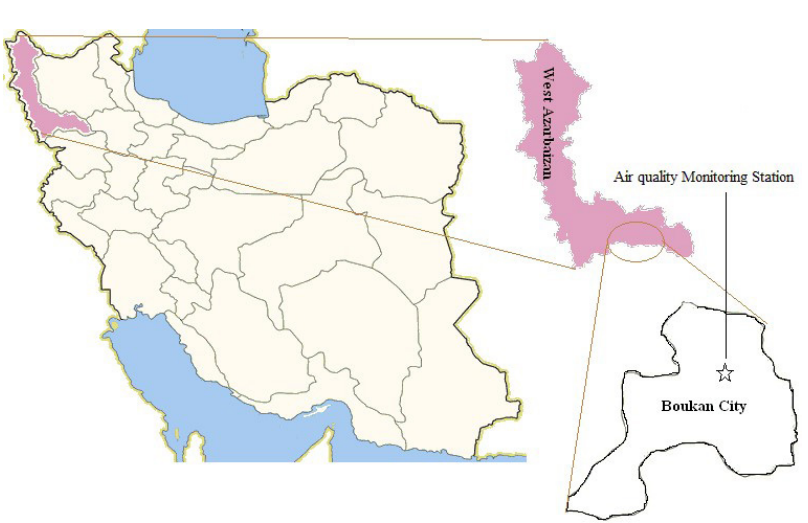

Figure 1. Location of the study area in Bukan City, West Azerbaijan, Iran.

1

- Data Collection From Monitoring Stations

2

- Excel spreadsheet
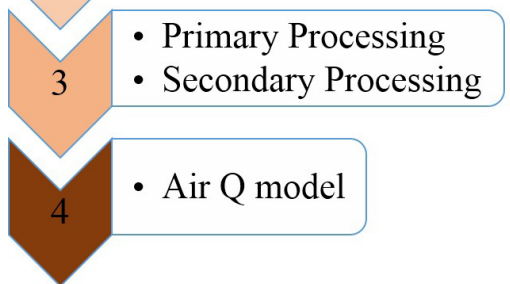

Figure 2. Flowchart of use of Air Q software (4 steps).

primary processing (removing, sheeting, integration time), secondary processing (code writing in Excel, calculating $\mathrm{PM}_{10}$ and $\mathrm{PM}_{2.5}$ means, primary and secondary filtering of data). In this work, the interval of $10 \mu \mathrm{g} \mathrm{m}^{-3}$ was selected for assessing short-term health impacts. After data classification based on the interval of $10 \mu \mathrm{g} \mathrm{m}^{-3}$, the results were entered into the software.

\section{Air Quality software}

Air $\mathrm{Q}$ is a software that quantifies air pollution data. This work employed Air Q software, version 2.2.3. When working with the software, one air pollutant had to be selected for the assessment of its effect on health, and the data regarding population exposure to this pollutant was entered in the program. The data entered included coordinates (latitude and longitude), exposed population, number of stations used for profiling, mean and maximum concentrations (annual, winter, and summer), annual 98th percentile, baseline incidence (BI) per 100000 per year, and relative risk (RR) (mean, lower, and upper). For the predefined health outcomes, two options were given when calculating the health impact: to use WHO default values for BI and RR (95\% CI), the level of scientific certainty of which is given according to the available epidemiological evidence, or to replace the WHO default values with estimates for BI and RR obtained from local 
Table 1. Particle concentrations of $\mathrm{PM}_{10}$ and $\mathrm{PM}_{2.5}$ in different seasons of the year

\begin{tabular}{|c|c|c|c|c|c|c|}
\hline \multicolumn{7}{|c|}{$\mathrm{PM}_{10}\left(\mu \mathrm{g} \mathrm{m}^{-3}\right)$} \\
\hline Average & & & Maximu & & & $98^{\text {th }}$ Percentile \\
\hline Annual & Summer & Winter & Annual & Summer & Winter & \\
\hline 79.6 & 84.37 & 74.86 & 395.95 & 395.95 & 261.57 & 237.39 \\
\hline \multicolumn{7}{|c|}{$\mathbf{P M}_{25}\left(\mu \mathrm{g} \mathrm{m}^{-3}\right)$} \\
\hline Average & & & Maximu & & & $98^{\text {th }}$ Percentile \\
\hline Annual & Summer & Winter & Annual & Summer & Winter & \\
\hline 33.01 & 34.95 & 31.07 & 180.41 & 180.41 & 85.32 & 94.88 \\
\hline
\end{tabular}

epidemiological studies. In cases of the second option, the scientific uncertainty will be set to unknown by the program. In this research, the $\mathrm{BI}$ and $\mathrm{RR}$ values were selected based on similar studies $(23,24)$.

\section{Results}

Table 1 shows a descriptive analysis of $\mathrm{PM}_{10}$ and $\mathrm{PM}_{2.5}$ concentrations in the various seasons of 2015-2106. Table 2 shows the hourly average concentrations $\left(\mu \mathrm{g} \mathrm{m}^{-3}\right)$ of $\mathrm{PM}_{10}$ and $\mathrm{PM}_{2.5}$ at Bukan city from 2014 to 2015. Table 3 presents the RR with a $95 \% \mathrm{CI}$; this figure was used for the health effect estimates of $\mathrm{PM}_{10}$ and $\mathrm{PM}_{2.5}$ particles. The correlation between $\mathrm{PM}_{10}$ and $\mathrm{PM}_{2.5}$ concentrations and the percentage of estimated AP (attributed proportion, $\mathrm{RR}$, and estimated number of excess cases [persons]) are shown in Table 4. Figure 3 shows the correlation between cumulative excess and $\mathrm{PM}_{10}$ concentration, including total mortality, cardiovascular mortality, respiratory mortality, hospital admissions (HA) for respiratory disease, and HA for cardiovascular disease.

\section{Discussion}

The average concentration of particulate matter was higher in summer than in winter. The concentrations of $\mathrm{PM}_{10}$ in summer and winter were 84.37 and $74.86 \mu \mathrm{g} \mathrm{m}^{-3}$, respectively. The maximum concentration of $\mathrm{PM}_{10}$ was greater in summer $\left(395.95 \mathrm{~g} \mathrm{~m} \mathrm{~m}^{-3}\right)$. The concentrations of $\mathrm{PM}_{2.5}$ in summer and winter were 34.95 and $31.07 \mu \mathrm{g} \mathrm{m}^{-3}$, respectively (Table 1 ). The maximum concentration of $\mathrm{PM}_{2.5}$ was greater in summer $\left(180.41 \mu \mathrm{g} \mathrm{m}^{-3}\right)$. The results reported in Table 1 show that neither the $\mathrm{PM}_{10}$ nor the $\mathrm{PM}_{2.5}$ concentration changed significantly with seasonal variations; they were nearly constant. In recent years, dust storms have been the main causes of high $\mathrm{PM}_{10}$ and $\mathrm{PM}_{2.5}$ concentrations in summer compared with other seasons (1). In Iran, dust storms have both internal and
Table 2. Hourly average concentrations $(\mu \mathrm{g} \mathrm{m}-3)$ of $P M_{10}$ and $P M_{2.5}$ particles in Bukan City from 2015 to 2016

\begin{tabular}{|c|c|c|c|c|}
\hline & & $\begin{array}{c}\text { Maximum } \\
\left(\mu \mathrm{g} \mathrm{m}^{-3}\right)\end{array}$ & $\begin{array}{c}\text { Minimum } \\
\left(\mu \mathrm{g} \mathrm{m}^{-3}\right)\end{array}$ & $\begin{array}{c}\text { Mean } \\
\left(\mu \mathrm{g} \mathrm{m}^{-3}\right)\end{array}$ \\
\hline \multirow[t]{2}{*}{ January } & $\mathrm{PM}_{10}$ & 261.57 & 12.07 & 53.81 \\
\hline & $\mathrm{PM}_{2.5}$ & 49.7 & 4.74 & 29.62 \\
\hline \multirow[t]{2}{*}{ February } & $\mathrm{PM}_{10}$ & 230.72 & 19.92 & 75.33 \\
\hline & $\mathrm{PM}_{2.5}$ & 66.52 & 16.61 & 27.66 \\
\hline \multirow[t]{2}{*}{ March } & $\mathrm{PM}_{10}$ & 204.83 & 11.13 & 74.51 \\
\hline & $\mathrm{PM}_{2.5}$ & 85.32 & 19.17 & 32.7 \\
\hline \multirow[t]{2}{*}{ April } & $\mathrm{PM}_{10}$ & 179.11 & 19.31 & 62.48 \\
\hline & $\mathrm{PM}_{2.5}$ & 54.18 & 6.75 & 19.55 \\
\hline \multirow[t]{2}{*}{ May } & $\mathrm{PM}_{10}$ & 225.4 & 24.45 & 78.35 \\
\hline & $\mathrm{PM}_{2.5}$ & 27.45 & 7.33 & 27.45 \\
\hline \multirow[t]{2}{*}{ June } & $\mathrm{PM}_{10}$ & 395.95 & 6.92 & 97.5 \\
\hline & $\mathrm{PM}_{2.5}$ & 164.98 & 7.71 & 40.08 \\
\hline \multirow[t]{2}{*}{ July } & $\mathrm{PM}_{10}$ & 233.74 & 18.75 & 69.2 \\
\hline & $\mathrm{PM}_{2.5}$ & 140 & 5.93 & 27.67 \\
\hline \multirow[t]{2}{*}{ August } & $\mathrm{PM}_{10}$ & 144.99 & 17.05 & 62.55 \\
\hline & $\mathrm{PM}_{2.5}$ & 180.41 & 1.83 & 38.85 \\
\hline \multirow[t]{2}{*}{ September } & $\mathrm{PM}_{10}$ & 175.66 & 31.18 & 71.56 \\
\hline & $\mathrm{PM}_{2.5}$ & 99.91 & 1.25 & 32.49 \\
\hline \multirow[t]{2}{*}{ October } & $\mathrm{PM}_{10}$ & 248.99 & 3.16 & 75.05 \\
\hline & $\mathrm{PM}_{2.5}$ & 81.44 & 1.55 & 32.76 \\
\hline \multirow[t]{2}{*}{ November } & $\mathrm{PM}_{10}$ & 103.07 & 2.38 & 56.76 \\
\hline & $\mathrm{PM}_{2.5}$ & 64.26 & 8.33 & 23.66 \\
\hline \multirow[t]{2}{*}{ December } & $\mathrm{PM}_{10}$ & 116.62 & 3.02 & 49.54 \\
\hline & $\mathrm{PM}_{2.5}$ & 51.43 & 0.87 & 35.26 \\
\hline
\end{tabular}

external sources. The external sources of dust storms are the countries of Iraq, Jordan, and Saudi Arabia, and the internal sources are the provinces of Khuzestan, Kerman, and Sistan-Baluchistan. The reasons for the increase in dust storms in Iran include drought, lack of suitable vegetation, reduced rainfall and moisture in the air, destruction of forest and grasslands in Iraq, changes in air

Table 3. Relative risk with 95\% confidence interval and corresponding reference

\begin{tabular}{|c|c|c|c|c|c|}
\hline \multirow{2}{*}{ Health effects } & & \multirow{2}{*}{ Baseline Incidence } & \multicolumn{3}{|c|}{ Relative risk per $10 \mu \mathrm{g} \mathrm{m}^{-3}$} \\
\hline & & & Low & Medium & High \\
\hline \multirow[t]{3}{*}{ Mortality } & Total & 543.5 & 1.004 & 1.006 & 1.008 \\
\hline & Cardiovascular & 231 & 1.005 & 1.009 & 1.013 \\
\hline & Respiratory & 48.8 & 1.005 & 1.020 & 1.013 \\
\hline \multirow[t]{2}{*}{ Morbidity } & HA Respiratory Disease & 1260 & 1.005 & 1.008 & 1.011 \\
\hline & HA Cardiovascular Disease & 436 & 1.006 & 1.009 & 1.013 \\
\hline
\end{tabular}


Table 4. Health effects, relative risks, estimated AP, and estimated numbers of excess cases due to short-term exposure to PM10 levels above 10 $\mu \mathrm{g} \mathrm{m} \mathrm{m}^{-3}$

\begin{tabular}{|c|c|c|c|}
\hline Health effects & RR (Medium) & Estimated AP (\%) & Estimated number of excess cases (persons) \\
\hline \multirow[t]{3}{*}{ Total Mortality } & Central & 4.0332 & 49.3 \\
\hline & Lower & 2.7254 & 33.3 \\
\hline & Upper & 5.3062 & 64.9 \\
\hline \multirow[t]{3}{*}{ Cardiovascular mortality } & Central & 5.9302 & 30.8 \\
\hline & Lower & 3.3837 & 17.6 \\
\hline & Upper & 8.3458 & 43.4 \\
\hline \multirow[t]{3}{*}{ Respiratory mortality } & Central & 8.3458 & 9.2 \\
\hline & Lower & 3.3837 & 3.7 \\
\hline & Upper & 12.2876 & 13.5 \\
\hline \multirow[t]{3}{*}{ HA respiratory disease } & Central & 5.3062 & 150.4 \\
\hline & Lower & 3.2528 & 92.2 \\
\hline & Upper & 7.2743 & 206.2 \\
\hline \multirow[t]{3}{*}{ HA cardiovascular disease } & Central & 5.9302 & 58.2 \\
\hline & Lower & 4.0332 & 39.6 \\
\hline & Upper & 8.3458 & 81.9 \\
\hline
\end{tabular}
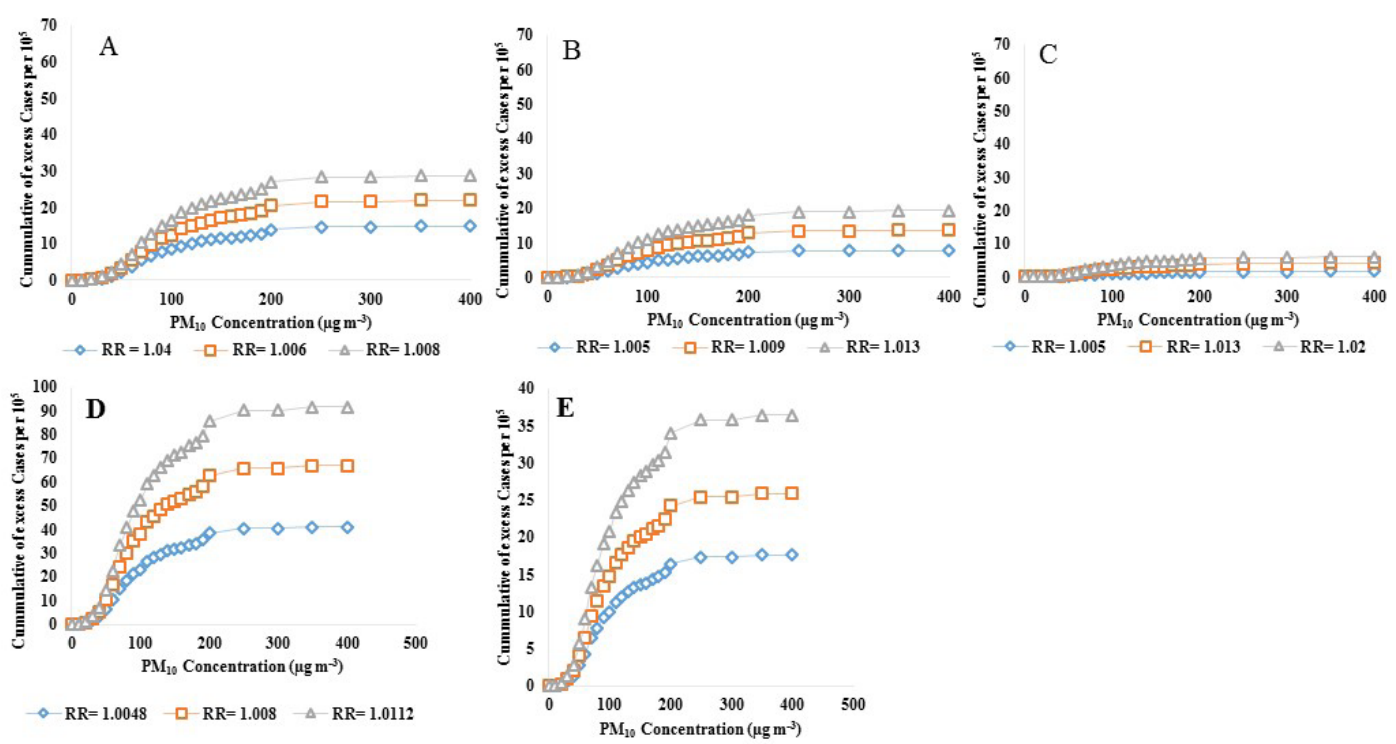

Figure 3. Cumulative excess of case related to $\mathrm{PM}_{10}$ concentration: $\mathbf{A}$ : total mortality, B: cardiovascular mortality, $\mathbf{C}$ : respiratory mortality, $\mathbf{D}$ : $\mathrm{HA}$ for respiratory disease, E: HA for cardiovascular disease.

pressure, and strong winds from the deserts of Iraq and Saudi Arabia. The WHO guidelines for $\mathrm{PM}_{10}$ and $\mathrm{PM}_{2.5}$ particles are 50 and $25 \mu \mathrm{g} \mathrm{m}^{-3}$, respectively (25). As shown in Table 2, the $\mathrm{PM}_{10}$ and $\mathrm{PM}_{25}$ concentrations measured in this study were higher than WHO guidelines in most months of the year.

The values shown in Table 3 were extracted from similar studies in Iran $(24,26)$. Illustrated in Table 3 are the health effects of $\mathrm{PM}_{10}$ particles that can be calculated in mortality, such as total mortality, cardiovascular mortality, respiratory mortality, and morbidity such as HA for respiratory disease and HA for cardiovascular disease. As illustrated in Table 4, the Air Q model predicted that the means of total mortality relative to $\mathrm{PM}_{10}$ and $\mathrm{PM}_{2.5}$ particles were 33.3 and 49.8 deaths, respectively. Figure 3, Part A shows the cumulative excess cases per 100000 related to total mortality (lower, mean, and upper). In 2015-2016, there were 935 deaths, 57 of which were due to driving accidents. In other words, 878 people suffered a non-accidental death. As a result, 3.79\% of total mortality was due to $\mathrm{PM}_{10}$ particles. Similar studies have shown that the effects of $\mathrm{PM}_{10}$ on total mortality were responsible for 2194 deaths in the city of Tehran in 2012 (24). Other studies have shown that the highest number of deaths caused by air pollution was related to $\mathrm{PM}_{10}$ particles (100 deaths) (27). The Air Q model predicted that 17.6 deaths (mean), or $2.004 \%$ of total mortality in Bukan City were related to cardiovascular mortality. Figure 3, Part B shows the cumulative excess of cases per 100000 related to cardiovascular mortality (lower, mean, and upper). Motalleby and colleagues' results showed that the effects of PM10 were responsible for 66 cardiovascular deaths in 
the city of Kashan in 2011 (27). The Air Q model predicted that 3.7 deaths from respiratory disease (mean) were related to the effects of $\mathrm{PM}_{10}$. As a result, $0.42 \%$ of the total mortality in Bukan City was due to respiratory mortality. Figure 3, Part $\mathrm{C}$ shows the cumulative excess of cases per 100000 related to cardiovascular mortality (lower, mean, and upper). The Air Q model predicted that 92.2 deaths (mean) were related to HA respiratory disease morbidity. Figure 3, Part D shows the cumulative excess of cases per 100000 related to cardiovascular mortality (lower, mean, and upper). The Air Q model predicted that 39.6 deaths (mean) were related to HA cardiovascular disease. Figure 3, Part E shows the cumulative excess of cases per 100000 related to cardiovascular mortality (lower, mean and upper). The continual evaluation of air quality data is necessary to investigate the effects of air pollution on human health.

\section{Conclusion}

This work used Air Quality software to assess the health risks of particulate matter. The health effects associated with particulate matter, such as total mortality, cardiovascular mortality, respiratory mortality, HA for respiratory disease morbidity, and HA for cardiovascular disease, were calculated.

This model can be useful in aiding data collection about the health effects of pollutants on exposed population.

\section{Authors' contributions}

All authors contributed equally and were involved in the study design, data collection, and article approval.

\section{Competing interests}

The authors of this article declare that they have no competing interests.

\section{Ethical issues}

The authors confirm that the research is their original study. It has not been published, nor is it under review in another journal, and it is not being submitted for publication elsewhere.

\section{Acknowledgments}

This study was supported by the Students Research Committee of Shahid Beheshti University of Medical Science, Iran (grant no. 2571).

\section{References}

1. Boloorani AD, Nabavi SO, Bahrami HA, Mirzapour F, Kavosi M, Abasi E, et al. Investigation of dust storms entering Western Iran using remotely sensed data and synoptic analysis. J Environ Health Sci Eng 2014; 12(1): 124. doi: 10.1186/s40201-014-0124-4.

2. Shahsavani A, Naddafi K, Jaafarzadeh Haghighifard $\mathrm{N}$, Mesdaghinia A, Yunesian $\mathrm{M}$, Nabizadeh $\mathrm{R}$, et al. Characterization of ionic composition of TSP and $\mathrm{PM}_{10}$ during the Middle Eastern Dust (MED) storms in Ahvaz, Iran. Environ Monit Assess 2012; 184(11): 6683-92. doi: 10.1007/s10661-011-2451-6.

3. Sowlat MH, Naddafi K, Yunesian M, Jackson PL, Lotfi S, Shahsavani A. PM 10 source apportionment in Ahvaz, Iran, using positive matrix factorization. CLEAN Soil Air Water 2013; 41(12): 1143-51. doi: 10.1002/clen.201200131.

4. Shao Y, Wyrwoll KH, Chappell A, Huang J, Lin Z, McTainsh GH, et al. Dust cycle: an emerging core theme in Earth system science. Aeolian Res 2011; 2(4): 181-204. doi:10.1016/j.aeolia.2011.02.001.

5. Seinfeld JH, Pandis SN. Atmospheric Chemistry and Physics. New York: John Wiley and Sons; 1998.

6. Anderson JO, Thundiyil JG, Stolbach A. Clearing the air: a review of the effects of particulate matter air pollution on human health. J Med Toxicol 2012; 8(2): 166-75. doi: 10.1007/s13181-011-0203-1.

7. Alizadeh Choobari O, Zawar-Reza P, Sturman A. The global distribution of mineral dust and its impacts on the climate system: a review. Atmospheric Research 2014; 138: 152-65.

8. Stedman JR, King K, Holland M, Walton H. Quantification of the health effects of air pollution in the UK for revised $\mathrm{PM}_{10}$ objective analysis. AEAT; 2002.

9. Xu LY, Yin H, Xie XD. Health risk assessment of inhalable particulate matter in Beijing based on the thermal environmentInt. J Environ Res Public Health 2014; 11(12): 12368-88. doi: 10.3390/ijerph111212368.

10. Sharafi K, Khosravi T, Moradi M, Pirsaheb M. Air quality and variations in $\mathrm{PM}_{10}$ pollutant concentration in western iran during a four -year period (2008-2011), kermanshah a case study. Journal of Engineering Science and Technology 2015; 10(1): 47-56.

11. Kavousi A, Sefidkar R, Alavimajd H, Rashidi Y, Abolfazli Khonbi Z. Spatial analysis of CO and $\mathrm{PM}_{10}$ pollutants in Tehran city. Journal of Paramedical Sciences 2013; 4(3): 4150 .

12. Tiwary A, Colls J. Air Pollution: Measurement, Modelling \& Mitigation. 3rd ed. London: Taylor and Francis Group; 2009.

13. Pengra B.The Drying of Iran's Lake Urmia and its Environmental Consequences. https://na.unep.net/geas/ getUNEPPageWithArticleIDScript.php?article_id=79. Accessed Oct 2016.

14. Gilmour PS, Brown DM, Lindsay TG, Beswick PH, MacNee W, Donaldson K. Adverse health effects of PM10 particles: involvement of iron in generation of hydroxyl radical. Occup Environ Med 1996; 53(12): 817-22.

15. Nordenhäll C, Pourazar J, Ledin M, Levin JO, Sandström T, Ädelroth E. Diesel exhaust enhances airway responsiveness in asthmatic subjects. Eur Respir J 2001; 17(5): 909-15.

16. Chuang KJ, Chan CC, Su TC, Lee CT, Tang CS. The effect of urban air pollution on inflammation, oxidative stress, coagulation, and autonomic dysfunction in young adults. Am J Respir Crit Care Med 2007; 176(4): 370-6. doi: 10.1164/rccm.200611-1627OC.

17. Bell ML, HEI Health Review Committee. Assessment of the health impacts of particulate matter characteristics. Res Rep Health Eff Inst 2012; (161): 5-38.

18. Evans J, Donkelaar AV, Martin RV, Burnett R, Rainham DG, Birkett NJ, et al. Estimates of global mortality attributable to particulate air pollution using satellite imagery. Environ Res 2013; 120: 33-42. doi: 10.1016/j.envres.2012.08.005.

19. Kamarehie B, Ghaderpoori M, Jafari A, Karami M, Mohammadi A. Quantification of health effects related to $\mathrm{SO} 2$ and $\mathrm{NO} 2$ pollutants using air quality model. J 
Adv Environ Health Res 2017; 5(1): 44-50. doi: 10.22103/ JAEHR.2017.47757.

20. World Health Organization (WHO). Quantification of the Health Effects of Exposure to Air Pollution Report of a WHO Working Group. The Netherlands: WHO; 2000.

21. Karbassi A, Nabi Bidhendi G, Pejman A, Esmaeili Bidhendi M. Environmental impacts of desalination on the ecology of Lake Urmia. J Great Lakes Res 2010; 36(3): 419-424. doi: 10.1016/j.jglr.2010.06.004.

22. Jalili S, Kirchner I, Livingstone DM, Morid S. The influence of large-scale atmospheric circulation weather types on variations in the water level of Lake Urmia, Iran. Int J Climatol 2012; 32(13): 1990-96.

23. Ghanbari Ghozikali M, Mosaferi M, Nadafi K. Quantification of the health effects of exposure to ozone in tabriz by using airq model. Urmia Med J 2014; 25(6): 52130. [In Persian].
24. Naddafi K, Hassanvand MS, Yunesian M, Momeniha F, Nabizadeh R, Faridi S, et al. Health impact assessment of air pollution in megacity of Tehran, Iran. Iranian J Environ Health Sci Eng 2012; 9(1): 28. doi: 10.1186/1735-2746-928.

25. WHO. Air quality guidelines: global update 2005: particulate matter, ozone, nitrogen dioxide, and sulfur dioxide. Geneva: World Health Organization; 2006.

26. Nourmoradi H, Goudarzi G, Daryanoosh SM, OmidiKhaniabadi F, Jourvand M, Omidi-Khaniabadi Y. Health impacts of particulate matter in air by Air Q model in Khorramabad city, Iran. J Basic Res Med Sci 2015; 2(2): 4452.

27. Motalleby M, Mazaheri A, Mosayebi M, Takhtfiroozeh SM. Assessing Health Impacts of Air Pollution in Kashan 2011. Arak Medical University Journal 2015; 18(5): 77-87. [In Persian]. 